\title{
BMJ Open Association between dyslipidemia and risk of type 2 diabetes mellitus in middle-aged and older Chinese adults: a secondary analysis of a nationwide cohort
}

\author{
Jieru Peng (D) , ${ }^{1}$ Fei Zhao, ${ }^{2}$ Xue Yang, ${ }^{3}$ Xiongfei Pan, ${ }^{4}$ Jue Xin, ${ }^{1}$ Mengjun $\mathrm{Wu},{ }^{5}$ \\ Yong G Peng ${ }^{6}$
}

To cite: Peng J, Zhao F, Yang X, et al. Association between dyslipidemia and risk of type 2 diabetes mellitus in middle-aged and older Chinese adults: a secondary analysis of a nationwide cohort. BMJ Open 2021;11:e042821. doi:10.1136/ bmjopen-2020-042821

- Prepublication history and additional supplemental material for this paper are available online. To view these files, please visit the journal online (http://dx.doi.org/10.1136/ bmjopen-2020-042821).

JP and FZ contributed equally.

Received 21 July 2020 Revised 07 March 2021 Accepted 12 April 2021

Check for updates

(C) Author(s) (or their employer(s)) 2021. Re-use permitted under CC BY-NC. No commercial re-use. See rights and permissions. Published by BMJ.

For numbered affiliations see end of article.

Correspondence to

Dr Mengjun Wu;

397550004@qq.com

\section{ABSTRACT}

Aims To evaluate the type 2 diabetes mellitus (T2DM) risk of individuals with different types of dyslipidaemia and compare the predictive value of distinct lipid parameters in predicting T2DM.

Methods We conducted a secondary analysis of data from the China Health and Retirement Longitudinal Study (CHARLS). 17708 individuals over 45 years old were interviewed, and 11847 blood samples were collected at the baseline survey (2011-2012). Outcome of T2DM was confirmed during two follow-up surveys (2013-2014 and 2015-2016). The HRs and 95\% Cl of T2DM associated with dyslipidaemia were estimated by Cox proportional hazards regressions model. The discriminatory value of eight lipid parameters were compared by the area under the receiver operating characteristic (ROC) curve (AUC).

Results A total of 7329 participants were enrolled in our analysis; during the mean follow-up time of 3.4 years, 387 (5.28\%) participants developed new-onset diabetes. Compared with participants in normal lipid levels, the T2DM risk of those with hypercholesterolaemia, hypertriglyceridaemia and low high-density lipoprotein cholesterol (HDL-C) were significantly increased (HRs $(95 \% \mathrm{Cl})$ were 1.48 (1.11 to 1.96$), 1.92$ (1.49 to 2.46 ) and 1.67 (1.35 to 2.07), respectively). The AUCs of non-HDL-C $(0.685,95 \% \mathrm{Cl} 0.659$ to 0.711$)$, triglyceride (TG) $(0.684$, $95 \% \mathrm{Cl} 0.658$ to 0.710$)$, total cholesterol (TC)/HDL-C $(0.685,95 \% \mathrm{Cl} 0.659$ to 0.712$)$ and TG/HDL-C $(0.680,95 \%$ $\mathrm{Cl} 0.654$ to 0.706$)$ were significantly $(\mathrm{p}<0.005)$ larger than that of other lipid parameters.

Conclusion Middle-aged and elderly adults with hypertriglyceridaemia, hypercholesterolaemia and low $\mathrm{HDL}-\mathrm{C}$ were at higher risk for developing diabetes. NonHDL-C, TG, TC/HDL and TG/HDL have greater performance than other lipid parameters in predicting T2DM incidence.

\section{INTRODUCTION}

Type 2 diabetes mellitus (T2DM) is an important problem for public health with 1 in 11 adults (463 million) has lived with diabetes in 2019. ${ }^{1}$ If the dramatical increase in its prevalence continues, 700 million more people of 20-79 years old will have T2DM in $2045 .^{2}$ It is reported that $12 \%$ of global health
Strengths and limitations of this study

- This study systematically compared the predictive power among different lipid profiles in forecasting type 2 diabetes mellitus.

- The study's subjects were obtained by multistage probability sampling from 28 provinces of China; our findings could apply to the general middle-aged and elderly Chinese population.

- The primary limitation of this study was that case of diabetes was defined by interviewee's self-report; lacking of clinical evaluation may lead to discrepancy with the actual situation.

expenditure is spent on diabetic care, and four out of five people with diabetes live in low-income and middle-income countries, especially like China, which has the largest number of adult patients with diabetes. ${ }^{3}$

Dyslipidaemia has recently been recognised as a risk factor for T2DM. A large prospective study among middle-aged adults conducted in the USA has shown the low levels of highdensity lipoprotein cholesterol (HDL-C) and elevated triglyceride (TG) levels were significantly related to the development with diabetes. ${ }^{4}$ A cohort study drawn from the Korean population found that the elevated concentration of total cholesterol (TC), lowdensity lipoprotein cholesterol (LDL-C) and TG were independent risk factors for development of new-onset T2DM. ${ }^{5}$ Moreover, increasing number of studies recently demonstrated that combined lipid parameters such as non-HDL-C, TG/HDL-C, LDL-C/HDL-C and TC/HDL-C were associated with T2DM ${ }^{67}$ and have superiority value in predicting the incident of T2DM. ${ }^{89}$ However, contradictory results about the relationship between dyslipidaemia and diabetes existed in different studies. 
Although the important role of combined lipid profiles in predicting T2DM has been gradually recognised, a systematic comparison on the predictive value of lipid parameter for T2DM has not been performed. Therefore, in this study, we aimed to: (1) estimate the T2DM risk of the middle-aged and older Chinese adults with different types of dyslipidaemia; (2) compare the predictive valuer of individual and combined lipid parameters in forecasting T2MD incidence.

\section{MATERIALS AND METHODS \\ Data source}

The study used the China Health and Retirement Longitudinal Study (CHARLS), ${ }^{10}$ a national representative research database from China. Considering regional and socioeconomic diversity across China, the CHARLS obtained a sample of the Chinese aged 45 years and older by multistage probability sampling from 28 provinces. The national baseline survey of CHARLS was commenced from 2011 and followed biennially at 2013 and 2015. The CHARLS database consisted participants' demographics background, health status and functioning, healthcare and insurance, work, retirement and pension, as well as anthropometric measurements. Informed consent was obtained from all participants.

\section{Study population}

A total of 17708 individuals were interviewed in the main CHARLS baseline survey, and 11847 blood samples were successfully collected. Among those with available serum lipid measurements, we first excluded subjects who selfreported a history of diabetes. Then, we excluded those who had incomplete decisive confounding variables, such as demographic information, anthropometric or biomarker records, individuals who had an undefined diabetic outcome due to lost to follow-up or data missing in 2013 or 2015.

\section{Estimating T2DM incidence}

An incident case of T2DM was defined as self-reported of doctor-diagnosed diabetes. Participants were required to answer the question, 'Have you been diagnosed with diabetes by a doctor?' during the follow-up. In addition, investigators would confirm the situation in the next interview through the question, 'Our records from your last interview show that you have had/not had diabetes, is this right?'. Individuals who at least once self-reported have been diagnosed with diabetes in 2013 or 2015 were defined as new-onset diabetes.

\section{Assessment of dyslipidaemia}

Concentrations of four classical serum lipid indices, including TC, TG, LDL-C and HDL-C, were tested from blood samples stored in the freezer by using the standard enzymatic colorimetric method. Dyslipidaemia was defined according to criterion published by the 2016 Chinese guidelines for the management of dyslipidaemia in adults. ${ }^{11}$ Dyslipidaemia was determined as a TC of $240 \mathrm{mg} / \mathrm{dL}(6.2 \mathrm{mmol} / \mathrm{L})$ or greater, TG level of $200 \mathrm{mg} /$ $\mathrm{dL}(2.3 \mathrm{mmol} / \mathrm{L})$ or greater, LDL-C level of $160 \mathrm{mg} / \mathrm{dL}$ $(4.1 \mathrm{mmol} / \mathrm{L})$ or greater and HDL-C level of $40 \mathrm{mg} / \mathrm{dL}$ $(1 \mathrm{mmol} / \mathrm{L})$ or less. Borderline high were defined if TC was $200-239 \mathrm{mg} / \mathrm{dL}$, TG was $150-199 \mathrm{mg} / \mathrm{dL}$ and LDL-C was $130-159 \mathrm{mg} / \mathrm{dL}$.

\section{Patient and public involvement}

Patients or the public were not involved in the design, or conduct, or reporting, or dissemination plans of our research.

\section{Statistical analysis}

Baseline characteristics of participants were described according to the diabetes status. Mean (SD) or median (IQR) were presented for normally and non-normally distributed continuous variables, respectively. Groups were compared using the independent t-test, and nonnormally distributed variables were compared after logarithmic transformation.

T-tests or Wilcoxon rank-sum test were used to analyse differences between different groups based on normality of distribution. Proportions were reported for categorical variables and compared with the help of the $\chi^{2}$ test or Fisher's exact test.

\section{Model building procedures}

Cox proportional hazards regression was used to estimate the risk of incident T2DM for participants with dyslipidaemia by calculating the HRs and $95 \%$ CIs in the crude models. Potential confounding factors were stepwise added into the adjusted models. Age, gender, education level and marriage status were controlled in the minimally models. The final models further adjusted for waist circumference, body mass index (BMI), systolic blood pressure, diastolic blood pressure, $\mathrm{C}$ reactive protein, plasma glucose, cigarette smoking and alcohol drinking. Moreover, stratified analysis was performed to examine the robustness of our research findings. Potential effect modification by stratifying variables were calculated by including cross-product term of the stratifying variable and the exposure into the fully adjusted model, and the likelihood ratio test was conducted to compare the models with or without a cross-product term.

\section{Comparing predictors performance}

We estimated the discriminatory value of eight parameters by computing the area under the receiver operating characteristic (ROC) curve (AUC) of multivariable-adjusted logistic models. Each regression model contained one lipid parameter and conventional risk factors. Lipid profiles included four classical lipid measures (TC, TG, HDL-C and LDL-C) and four combined lipid profiles (non-HDL-C, TC/HDL-C, TG/HDL-C and LDL-C/HDLC). The conventional risk factors included age, gender, waist circumference, BMI, systolic blood pressure, diastolic blood pressure, cigarette smoking and alcohol consumption. The statistic differences in AUCs were 


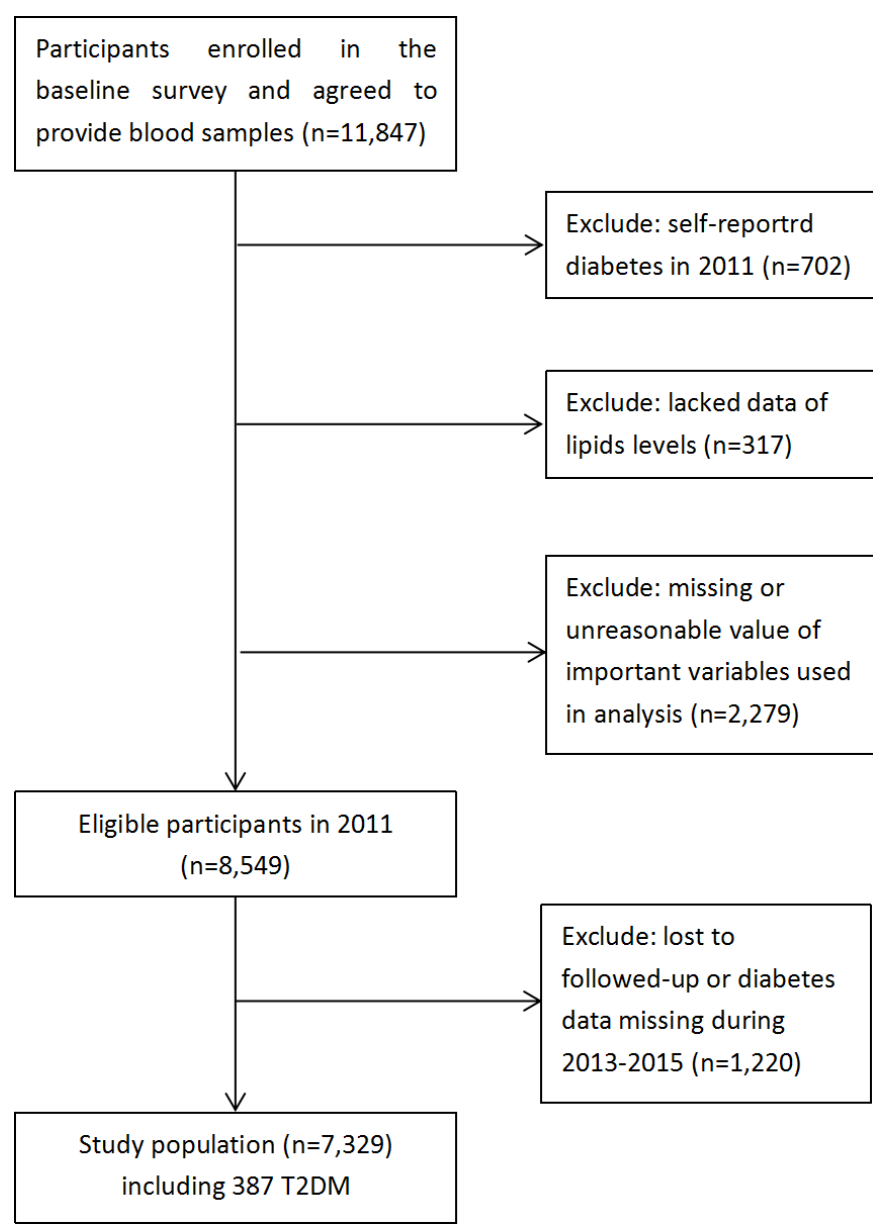

Figure 1 Flow chart of the study population according to inclusion and exclusion criteria.

compared by using an algorithm developed by DeLong et $a l^{12}$

Stata V.15 (StataCorp, College Station, Texas, USA) was used to perform all analyses. All tests were two sided, and statistical significance was defined as $p$ values $<0.05$.

\section{RESULTS}

\section{Baseline characteristics}

A total of 7329 participants were included in our analysis. A flow chart of the study population is given in figure 1 . During the mean follow-up time of 3.4 years, 387 participants had been diagnosed as diabetes, and the incidence rate of diabetes was $5.74 \%$. The mean (SD) age of all individuals at baseline was 58.77 (9.40) years. There were 3455 men account for $47.14 \%$. A total of $819(11.17 \%)$ participants defined as hypercholesterolaemia. The median (IQR) of TC, TG, LDL-C, HDL-C levels at baseline were 190.98 (167.40-215.34) mg/dL, 104.43 (74.34152.22) $\mathrm{mg} / \mathrm{dL}, 114.43$ (93.17-136.86) $\mathrm{mg} / \mathrm{dL}$ and 49.87 (40.59-60.31) $\mathrm{mg} / \mathrm{dL}$, respectively. The mean ratios (SD) of TC to HDL-C, TG to HDL-C and LDL-C to HDL-C were 4.06 (1.45), 3.14 (4.09) and 2.42 (0.94), respectively. The baseline characteristics of all participants and a characteristics comparison of individuals with different
TC classifications presented in table 1. Participants with hypercholesterolaemia at baseline survey had a disposition to be female and revealed higher age, BMI, waist circumference, blood pressure and fasting blood glucose.

\section{The T2DM risk of dyslipidaemia}

Table 2 presents the unadjusted and multivariableadjusted HRs and 95\% CI for diabetes according to dyslipidaemia status. At the primary models without any cofounding factors, all types of dyslipidaemia were associated with significantly increased T2DM risk. Compared with the normal subgroup, the HRs $(95 \% \mathrm{CI})$ of T2DM in the hypercholesterolaemia ( $\mathrm{TC} \geq 240 \mathrm{mg} / \mathrm{dL}$ ), hypertriglyceridaemia (TG $\geq 200 \mathrm{mg} / \mathrm{dL}$ ), elevated LDL-C (LDL-C $\geq 160 \mathrm{mg} / \mathrm{dL}$ ) and low HDL-C (HDL-C $<40 \mathrm{mg}$ / dL) subgroups were 1.77 (1.34-2.33), 2.56 (2.03-3.23), 1.55 (1.17-2.05) and 1.94(1.59-2.38), respectively. After gradually adjusting for potential influence factors, the associations were modestly attenuated but still statistically significant. The HRs $(95 \% \mathrm{CI})$ were 1.48 (1.11 to 1.96$)$, 1.92 (1.49 to 2.46) and 1.67 (1.353to 2.07) in the fully adjusted models, respectively. However, the statistically significant association between elevated LDL-C level and diabetes did not remain at further adjusted model (HR $0.93,94 \%$ CI 0.62 to 1.41 ). Baseline borderline high TG was associated with a $58 \%$ (HR $1.58,95 \%$ CI 1.21 to 2.07 ) increase in the risk of T2DM after adjusting for potential confounders. In addition, no statistically significant heterogeneity was observed for the associations between dyslipidaemia and diabetes in subgroups stratified by different impact factors including age, gender, waist circumference, systolic blood pressure, diastolic blood pressure, education level, cigarette smoking, alcohol consumption and BMI. The results were presented by forest plot figures in online supplemental figures 1-4.

\section{The performance of lipid parameters in predicting T2DM}

As listed in table 3, after the same adjustment for potential confounding factors, levels of non-HDL-C, TC, TG, ratios of TC to HDL-C, TG to HDL-C and LDL-C to HDL-C were positive significantly associated with incidence of T2DM $(\mathrm{p}<0.05)$. HDL-C and T2DM shown a significantly negative relationship $(p=0.001)$. The statistically significant association between LDL-C and T2DM was not observed in our study $(\mathrm{p}=0.396)$. The AUCs that indicate the predictive performance of models are shown in table 3 . The AUCs were compared between models including various lipid parameters respectively in addition to conventional risk factors and the reference model including only conventional risk factors. The AUCs for models of non HCL-C (AUC $0.685,95 \%$ CI 0.659 to 0.711 ), TG (AUC $0.684,95 \%$ CI 0.658 to 0.710 ), ratio of TC to HDL-C (AUC $0.685,95 \%$ CI 0.659 to 0.712 ) and ratio of TG to HDL-C (AUC $0.680,95 \%$ CI 0.654 to 0.706 ) combined with conventional factors were significantly larger than that of model that only contained conventional factors (AUC $0.672,95 \%$ CI 0.646 to 0.700 ). The ROC curves of four parameters that significantly increased the AUC 
Table 1 Characteristics of study participants at baseline in the China Health and Retirement Longitudinal Study (CHARLS), 2011

\begin{tabular}{|c|c|c|c|c|c|}
\hline Baseline & All participants, $\mathrm{N}(\%)$ & \multicolumn{4}{|c|}{ Classifications of each lipid parameter, N (\%) } \\
\hline TC & $\begin{array}{l}190.98(167.40- \\
215.34)^{\star}\end{array}$ & Normal $(<200 \mathrm{mg} / \mathrm{dL})$ & $\begin{array}{l}\text { Borderline high (200- } \\
240 \mathrm{mg} / \mathrm{dL})\end{array}$ & \multicolumn{2}{|l|}{$\begin{array}{l}\text { Hypercholesterolaemia } \\
(\geq 240 \mathrm{mg} / \mathrm{d})\end{array}$} \\
\hline $\mathrm{N}(\%)$ & $7329(100)$ & $4431(60.46)$ & $2079(28.37)$ & \multicolumn{2}{|l|}{$819(11.17)$} \\
\hline TG & $104.43(74.34-152.22)^{*}$ & Normal $(<150 \mathrm{mg} / \mathrm{dL})$ & $\begin{array}{l}\text { Borderline high (150- } \\
200 \mathrm{mg} / \mathrm{dL} \text { ) }\end{array}$ & \multicolumn{2}{|l|}{$\begin{array}{l}\text { Hypertriglyceridaemia } \\
(\geq 200 \mathrm{mg} / \mathrm{dL})\end{array}$} \\
\hline N (\%) & $7329(100)$ & 5445 (74.29) & $883(12.05)$ & \multicolumn{2}{|l|}{$1001(13.66)$} \\
\hline LDL-C & $114.43(93.17-136.86)^{*}$ & Normal $(<130 \mathrm{mg} / \mathrm{dL})$ & $\begin{array}{l}\text { Borderline high (130- } \\
160 \mathrm{mg} / \mathrm{dL})\end{array}$ & \multicolumn{2}{|l|}{$\begin{array}{l}\text { Elevated LDL-C } \\
\text { ( } \geq 160 \mathrm{mg} / \mathrm{dL})\end{array}$} \\
\hline $\mathrm{N}(\%)$ & $7329(100)$ & $5010(68.36)$ & $1528(21.12)$ & \multicolumn{2}{|l|}{$771(10.52)$} \\
\hline HDL-C & $49.87(40.59-60.31)^{\star}$ & Normal ( $\geq 40 \mathrm{mg} / \mathrm{dL})$ & \multicolumn{3}{|l|}{$\begin{array}{l}\text { Low HDL-C (<40 mg/ } \\
\text { dL) }\end{array}$} \\
\hline $\mathrm{N}(\%)$ & $7329(100)$ & $5625(76.75)$ & \multicolumn{3}{|l|}{$1704(23.25)$} \\
\hline & & \multicolumn{3}{|c|}{ Characteristics based on classifications of total cholesterol } & $\mathbf{P}$ \\
\hline Age (years) & $58.77 \pm 9.40$ & $58.40 \pm 9.57$ & $59.25 \pm 9.16$ & $59.66 \pm 8.84$ & $<0.001$ \\
\hline $\mathrm{BMI}\left(\mathrm{kg} / \mathrm{m}^{2}\right)$ & $23.40 \pm 3.72$ & $23.18 \pm 3.64$ & $23.65 \pm 3.81$ & $24.09 \pm 3.84$ & $<0.001$ \\
\hline $\begin{array}{l}\text { Waist circumference } \\
\text { (cm) }\end{array}$ & $83.93 \pm 12.28$ & $83.15 \pm 12.31$ & $85.02 \pm 11.76$ & $85.52 \pm 13.03$ & $<0.001$ \\
\hline SBP $(\mathrm{mm} \mathrm{Hg})$ & $129.51 \pm 21.22$ & $128.15 \pm 20.99$ & $130.84 \pm 21.55$ & $133.69 \pm 20.92$ & $<0.001$ \\
\hline DBP (mm Hg) & $75.41 \pm 12.11$ & $74.66 \pm 12.09$ & $76.17 \pm 12.02$ & $77.63 \pm 12.13$ & $<0.001$ \\
\hline $\begin{array}{l}\text { C reactive protein } \\
\text { (mg/L) }\end{array}$ & $0.99(0.54-2.09)^{*}$ & $0.92(0.51-2.06)^{\star}$ & $1.04(0.56-1.99)^{*}$ & $1.18(0.65-2.36)^{*}$ & $<0.001$ \\
\hline $\begin{array}{l}\text { Plasma glucose } \\
\text { (mg/dL) }\end{array}$ & $102.24(94.32-112.68)^{\star}$ & $100.8(93.42-110.70)^{\star}$ & $103.5(95.22-113.94)^{\star}$ & $106.20(97.20-120.24)^{\star}$ & 0.004 \\
\hline Gender, n (\%) & & & & & $<0.001$ \\
\hline Male & $3455(47.14)$ & $2292(51.73)$ & $880(42.33)$ & $283(34.55)$ & \\
\hline Female & $3874(52.86)$ & $2139(48.27)$ & $1199(57.67)$ & $536(65.45)$ & \\
\hline
\end{tabular}

Education level, $\mathrm{n}$

(\%)

\begin{tabular}{|c|c|c|c|c|c|}
\hline Illiterate & $2163(29.51)$ & $1384(31.23)$ & $583(28.04)$ & $196(23.93)$ & \\
\hline Primary or above & 5166 (70.49) & 3047 (68.77) & 1496 (71.96) & $623(76.07)$ & \\
\hline $\begin{array}{l}\text { Marital Status, } n \\
(\%)\end{array}$ & & & & & 0.003 \\
\hline $\begin{array}{l}\text { Married/ } \\
\text { cohabitation }\end{array}$ & 6499 (88.68) & $3938(88.87)$ & $1858(89.37)$ & $703(85.84)$ & \\
\hline Single/divorced & 830 (11.32) & $493(11.13)$ & $221(10.63)$ & $116(14.16)$ & \\
\hline $\begin{array}{l}\text { Cigarette smoking, } \\
\mathrm{n}(\%)\end{array}$ & & & & & $<0.001$ \\
\hline Never smoke & $4473(61.03)$ & $2572(58.05)$ & $1241(64.50)$ & 560 (68.38) & \\
\hline Used to smoke & $593(8.09)$ & 338 (7.63) & 186 (8.95) & $69(8.42)$ & \\
\hline Still have & 2263 (30.88) & 1521 (34.33) & $552(26.55)$ & $190(23.20)$ & \\
\hline $\begin{array}{l}\text { Alcohol drinking, } n \\
\text { (\%) }\end{array}$ & & & & & 0.021 \\
\hline Never drink & $4848(66.15)$ & 2916 (65.81) & $1358(65.32)$ & 574 (70.09) & \\
\hline Used to drinking & $576(7.86)$ & 387 (8.73) & 144 (6.93) & 45 (5.49) & \\
\hline Still have & 1905 (25.99) & 1128 (25.46) & 577 (27.75) & 200 (24.42) & \\
\hline
\end{tabular}

*Variables are presented as median (IQR).

BMI, body mass index; DBP, diastolic blood pressure; HDL-C, high density lipoprotein cholesterol; LDL-C, low density lipoprotein cholesterol; SBP, systolic blood pressure; TC, total cholesterol; TG, triglyceride. 
Table $2 \mathrm{HR}(95 \% \mathrm{Cl})$ for diabetes in relation to total cholesterol, triglycerides, low-density lipoprotein cholesterol and highdensity lipoprotein cholesterol concentration (CHARLS 2011-2015)

\begin{tabular}{|c|c|c|c|}
\hline & Model 1 & Model 2 & Model 3 \\
\hline \multicolumn{4}{|l|}{ TC } \\
\hline Normal (<200 mg/dL) & 1 & 1 & 1 \\
\hline bBorderline high (200-240 mg/dL) & $1.33(1.08-1.65)$ & $1.27(1.03-1.58)$ & $1.19(0.95-1.48)$ \\
\hline Hypercholesterolaemia ( $\geq 240 \mathrm{mg} / \mathrm{dL}$ ) & $1.77(1.34-2.33)$ & $1.64(1.22-2.17)$ & $1.48(1.11-1.96)$ \\
\hline \multicolumn{4}{|l|}{ TG } \\
\hline Normal (<150mg/dL) & 1 & 1 & 1 \\
\hline Borderline high (150-200 mg/dL) & $2.00(1.55-2.61)$ & $1.91(1.46-2.48)$ & $1.58(1.21-2.07)$ \\
\hline Hypertriglyceridaemia ( $\geq 200 \mathrm{mg} / \mathrm{dL}$ ) & $2.56(2.03-3.23)$ & $2.46(1.93-3.13)$ & $1.92(1.49-2.46)$ \\
\hline \multicolumn{4}{|l|}{ LDL-C } \\
\hline Normal (<130 mg/dL) & 1 & 1 & 1 \\
\hline Borderline high (130-160 mg/dL) & $1.14(0.90-1.40)$ & $0.91(0.69-1.20)$ & $0.86(0.65-1.14)$ \\
\hline Elevated LDL-C ( $(2160 \mathrm{mg} / \mathrm{dL})$ & $1.55(1.17-2.05)$ & $0.99(0.66-1.85)$ & $0.93(0.62-1.41)$ \\
\hline \multicolumn{4}{|l|}{ HDL-C } \\
\hline Normal ( $\geq 40 \mathrm{mg} / \mathrm{dL})$ & 1 & 1 & 1 \\
\hline Low HDL-C (<40 mg/dL) & $1.94(1.59-2.38)$ & $2.15(1.75-2.63)$ & $1.67(1.35-2.07)$ \\
\hline
\end{tabular}

Model 1: not adjusted.

Model 2: model 1 adjusted for age (continuous, years), gender (male and female), education (illiterate, primary or above) and marital status (married/cohabitation, single/divorced).

Model 3: model 2 adjusted for waist circumference (continuous, $\mathrm{cm}$ ), body mass index (continuous, $\mathrm{kg} / \mathrm{m}^{2}$ ), diastolic blood pressure (continuous, $\mathrm{mm} \mathrm{Hg}$ ), systolic blood pressure (continuous, $\mathrm{mm} \mathrm{Hg}$ ), C reactive protein $(\mathrm{mg} / \mathrm{L}$ ), plasma glucose $(\mathrm{mg} / \mathrm{dL})$, cigarette smoking (never smoke, used to smoke or still have) and alcohol drinking (never drink, used to drinking or still have).

BMI, body mass index; CHARLS, China Health and Retirement Longitudinal Study; HDL-C, high density lipoprotein cholesterol; LDL-C, low density lipoprotein cholesterol; TC, total cholesterol; TG, triglyceride.

when added into the reference model were presented in the online supplemental figure 5 .

\section{DISCUSSION}

This current study aimed to compare the predictive power of different lipid profiles in forecasting T2DM. Meanwhile, we assess the T2DM risk among individuals with four different types of dyslipidaemia in a population-representative cohort in China. There were several important findings. Participants with borderline high TG, hypercholesterolaemia, hypertriglyceridaemia and low HDL-C suffered a higher T2DM risks through our 5-year national longitudinal study. Furthermore, non-HDL-C, TG, ratio of TC to HDL-C and ratio of TG to HDL-C provide better performance for T2DM prediction than other lipid panels. Our findings add the current evidence demonstrating that TC, TG and low HDL-C are risk factors for diabetes and emphasise that serum TG and combined lipid parameters were more efficient predictor factor for diabetes versus other lipid profiles.

In the present study, participants with hypercholesterolaemia, hypertriglyceridaemia and low HDL-C were $1.48,1.92$ and 1.67 , respectively, times more likely to develop T2DM compared with those without, which is accordant with some previously reported studies conducted in western country and Asian. A 5-year follow-up of 3951 initially non-diabetic participants from the Insulin Resistance Atherosclerosis Study showed that participants with high TGs $(>1.68 \mathrm{mmol} / \mathrm{L})$ and low level of HDL-C $(<1.06 \mathrm{mmol} / \mathrm{L})$ were at increased risk developing diabetes (relative risk 2.27, $95 \%$ CI 1.59 to 3.25 and RR 2.07, 95\% CI 1.45 to 3.13). ${ }^{13}$ A prospective 8 -year follow-up of the Tianjin General Hospital cohort of 7241 participants without prior diabetes or cardiovascular disease showed that high TG level (TG $\geq 2.26 \mathrm{mmol} / \mathrm{L}$ ) was correlated with an increased risk of developing T2DM (HR 1.54, 95\% CI 1.24 to 1.90$).{ }^{14}$ During 10 -year follow-up, individuals with dyslipidaemia were 1.7 times more likely to develop T2DM than those with normal serum lipid measures (OR $1.70,95 \%$ CI 1.23 to 2.34 ). ${ }^{15}$ The fifth Framingham Offspring study revealed that, compared with participants with normal lipid profiles, men with HDL-C level $<40 \mathrm{mg} /$ dL or women with HDL-C $<50 \mathrm{mg}$ / $\mathrm{dL}$ had 2.55 times risk of progressing to diabetes, and participants with TG level $\geq 150 \mathrm{mg} / \mathrm{dL}$ had 1.75 times risk of progressing to diabetes. ${ }^{4}$ On the whole, individuals with dyslipidaemia were at higher risk of incident T2DM; dyslipidaemia may be a risk factor for T2DM.

Even though LDL-C was generally acknowledged as a key factor of cardiovascular diseases, it is still controversial 


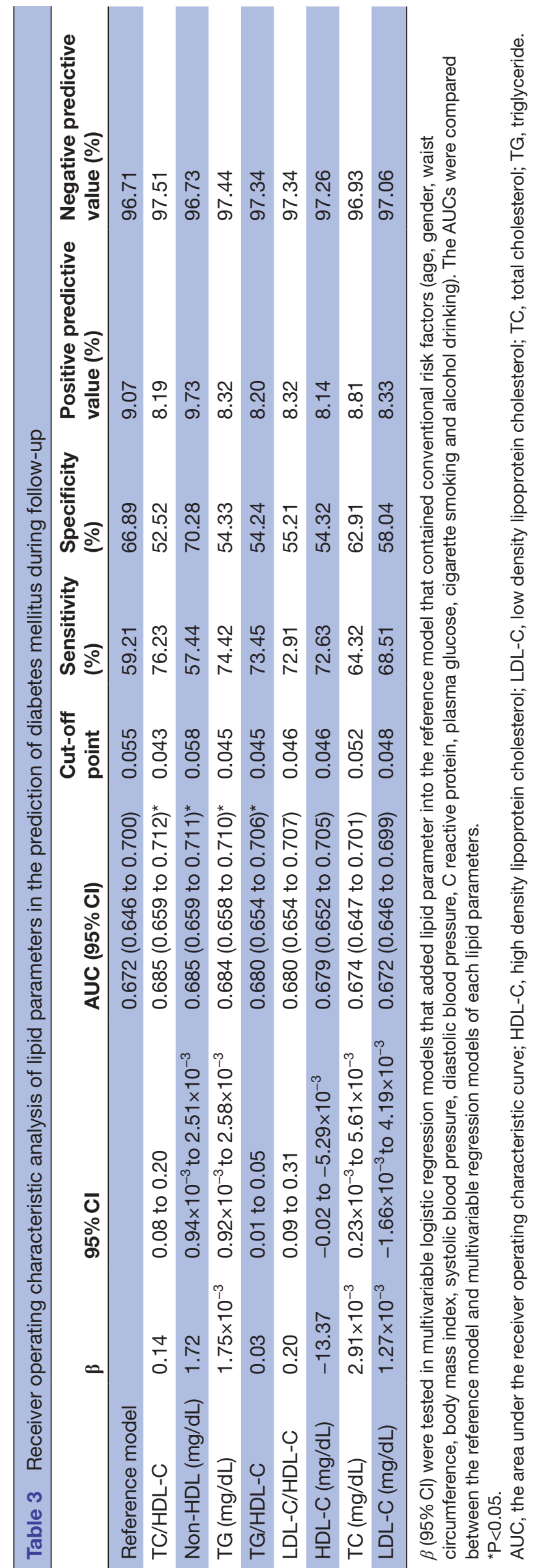

whether high or low LDL-C level would affect diabetes development. In our study, elevated LDL-C ( $\geq 160 \mathrm{mg} /$ $\mathrm{dL}$ ) did not arise a significant increase of T2DM. However, genetic researches shown reduced LDL-C may be a protective factor for T2DM. A 1-SD genetically instrumented elevation in LDL-C levels (equivalent to $38 \mathrm{mg}$ / $\mathrm{dL}$ ) was associated with a lower risk of diabetes (OR 0.79, 95\% CI 0.71 to 0.88$).{ }^{16}$ Another genetic meta-analysis illustrated that LDL-C lowering genetic variants in or near NPC1L1 were associated with a higher risk of T2DM. ${ }^{17}$ Further investigations are needed to identify the relationship between LDL-C and diabetes.

Blood lipid profiles are indexes in predicting risk of T2DM. Our study suggested that non-HDL-C, TG, TG/ HDL-C and TC/HDL-C were better marker among all lipid profiles for predicting the future incident of diabetes. Current US and European guidelines recommend the assessment of non-HDL-C calculated as TC minus HDL cholesterol for cardiovascular risk estimation. ${ }^{11} 18$ The role of non-HDL-C in predicting incident T2DM was also emphasised recently by other three studies. ${ }^{19-21}$ The discrimination ability of TG was equivalent to other well-known T2DM risk factors, such as fasting plasma glucose and waist circumference for predicting T2DM at follow-up. ${ }^{7}$ Numerous studies have provided consistent evidence that TG/HDL-C ratio may be a favourable predictor of future incident of T2DM. A meta-analysis showed that $\lg$ (TG/HDL-C) has better ability to reflect the risk of T2DM with standardised mean difference of 1.78 (95\% CI 1.04 to 2.52) than other methodology including TG, HDL-C and LDL-C. ${ }^{22}$ A cross-sectional study found that TC/HDL-C (AUC 0.684, 95\% CI 0.663 to 0.705$)$ was the best predictor among lipid profiles which followed by TG/HDL-C (AUC $0.666,95 \%$ CI 0.643 to 0.688 ) and non-HDL-C (AUC $0.656,95 \%$ CI 0.634 to $0.679){ }^{20}$

Some studies have shown that lipoproteins will have some effects on $\beta$-cell insulin secretion and glucose metabolism, which indirectly indicated that dyslipidaemia plays a role in the development of diabetes. A cohort study stated that the decrease of insulin secretory capacity may due to increased serum TC level. ${ }^{23}$ An experimental study on Min6 cells and primary islets discovered the function of HDL-C to promote the insulin secretion of pancreatic beta-cells and to enhance the glucose uptake by skeletal muscle, which elevates the potentiality that the low HDL-C concentration may exacerbate blood glucose control or accelerate the progression of pre-diabetes to diabetes mellitus. ${ }^{24}$ A systematic review concluded hypercholesterolaemia and low HDL-C levels may accelerate the development of beta-cell dysfunction under available evidence. This review proposed that cholesterol efflux obstructed by defective HDL could bring about accumulation of cholesterol in beta-cells, induce hyperglycaemic, damaged insulin secretion and $\beta$-cell apoptosis. $^{25}$ 
Strengths of our study included the following: (1) the data we used derived from a nationally representative survey with a large-scale sample size; (2) notwithstanding a relatively long follow-up term, the rate of lost to follow-up was low; (3) previous studies usually focused on one cholesterol component; however, our study analysed the predictive effects of eight different lipid profiles on diabetes. Several limitations should also be acknowledged. Firstly, previous studies indicated that family history of diabetes and environmental factors including physical inactivity and caloric excess play a key role in the development of the disease. ${ }^{2627}$ Hence, there is no control over family history of diabetes and environmental factors that may have an influence on our results. Secondly, the biochemical indicators levels only be detected once at baseline survey, and the biochemical parameters during the follow-up were absent because the blood samples were not collected during the subsequent follow-up. It needs further investigation in this filed. Third, in our study, cases of diabetes mellitus were defined if interviewees self-reported that they had been diagnosed with diabetes during the follow-up period. Lacking of clinical evaluation may lead to discrepancy with the actual situation. Nevertheless, we performed the sensitivity analysis by removing the individuals who reported diabetes mellitus in 2013 to confirm the association and found a similar association between dyslipidaemia symptom and diabetes. The result indicates the association is stable in Chinese middle-aged and elderly adults.

\section{CONCLUSION}

In conclusion, our prospective cohort study identifies distinct relationships of major lipid fractions and risk of development to T2DM. Middle-aged and elderly adults with hypertriglyceridaemia, hypercholesterolaemia and low HDL-C are at higher risk for diabetes. Non-HDL-C, TG, TC/HDL and TG/HDL have superior value than other lipid profiles in predicting diabetes incidence. These findings provide detailed data for the future more effective prevention of T2DM to support.

\footnotetext{
Author affiliations

'Department of Medical Records Statistics, Chengdu Women and Children' s Central Hospital, School of medicine, University of Electronic Science and Technology,

Chengdu, Sichuan, China

${ }^{2}$ Department of Infection Control, Sichuan University West China Second University Hospital, Chengdu, Sichuan, China

${ }^{3}$ West China School of Public Health and West China Fourth Hospital, Sichuan University, Chengdu, Sichuan, China

${ }^{4}$ Department of Epidemiology and Biostatistics, Ministry of Education Key Laboratory of Environment and Health and State Key Laboratory of Environmental Health (incubation), School of Public Health, Tongji Hospital of Tongji Medical College of Huazhong University of Science and Technology, Wuhan, Hubei, China

${ }^{5}$ Department of Anesthesiology, Chengdu Women and Children's Central Hospital, School of medicine, University of Electronic Science and Technology, Chengdu, Sichuan, China

${ }^{6}$ Department of Anesthesiology, University of Florida College of Medicine, Gainesville, Florida, USA
}

Acknowledgements We would like to thank the China Center for Economic Research, National School of Development at Peking University for providing the China Health and Retirement Longitudinal Study (CHARLS) data.

Contributors JP, FZ and XY performed the data analyses and wrote the manuscript; $X P$ and $M W$ contributed to the conception of the study and manuscript preparation; JX helped perform the analysis with constructive discussions; YGP revised the manuscript critically for important intellectual content.

Funding The authors have not declared a specific grant for this research from any funding agency in the public, commercial or not-for-profit sectors.

Disclaimer The sponsor has no role in the study design, and collection, analysis or interpretation of data.

Competing interests None declared.

Patient consent for publication Not required.

Ethics approval The CHARLS study data are publicly available and are open to researchers all over the world. Our study is a secondary analysis by using the deidentified CHARLS public data. The original CHARLS was approved by the Ethical Review Committee of Peking University, and all participants signed informed consent at the time of participation.

Provenance and peer review Not commissioned; externally peer reviewed.

Data availability statement Data are available and can be obtained from CHARLS database (http://charls.pku.edu.cn) with open access.

Supplemental material This content has been supplied by the author(s). It has not been vetted by BMJ Publishing Group Limited (BMJ) and may not have been peer-reviewed. Any opinions or recommendations discussed are solely those of the author(s) and are not endorsed by BMJ. BMJ disclaims all liability and responsibility arising from any reliance placed on the content. Where the content includes any translated material, BMJ does not warrant the accuracy and reliability of the translations (including but not limited to local regulations, clinical guidelines, terminology, drug names and drug dosages), and is not responsible for any error and/or omissions arising from translation and adaptation or otherwise.

Open access This is an open access article distributed in accordance with the Creative Commons Attribution Non Commercial (CC BY-NC 4.0) license, which permits others to distribute, remix, adapt, build upon this work non-commercially, and license their derivative works on different terms, provided the original work is properly cited, appropriate credit is given, any changes made indicated, and the use is non-commercial. See: http://creativecommons.org/licenses/by-nc/4.0/.

ORCID iD

Jieru Peng http://orcid.org/0000-0002-2789-3019

\section{REFERENCES}

1 Saeedi P, Petersohn I, Salpea P, et al. Global and regional diabetes prevalence estimates for 2019 and projections for 2030 and 2045: Results from the International Diabetes Federation Diabetes Atlas, $9^{\text {th }}$ edition. Diabetes Res Clin Pract 2019;157:107843.

2 Zhang P, Zhang X, Brown J, et al. Global healthcare expenditure on diabetes for 2010 and 2030. Diabetes Res Clin Pract 2010;87:293-301.

3 Guariguata L, Whiting DR, Hambleton I, et al. Global estimates of diabetes prevalence for 2013 and projections for 2035. Diabetes Res Clin Pract 2014;103:137-49.

4 Wilson PWF, Meigs JB, Sullivan L, et al. Prediction of incident diabetes mellitus in middle-aged adults: the Framingham offspring study. Arch Intern Med 2007;167:1068-74.

5 Seo MH, Bae JC, Park SE, et al. Association of lipid and lipoprotein profiles with future development of type 2 diabetes in nondiabetic Korean subjects: a 4-year retrospective, longitudinal study. J Clin Endocrinol Metab 2011;96:E2050-4.

6 Wang Y-L, Koh W-P, Talaei M, et al. Association between the ratio of triglyceride to high-density lipoprotein cholesterol and incident type 2 diabetes in Singapore Chinese men and women. $J$ Diabetes 2017;9:689-98.

7 Wang B, Zhang M, Liu Y, et al. Utility of three novel insulin resistancerelated lipid indices for predicting type 2 diabetes mellitus among people with normal fasting glucose in rural China. $J$ Diabetes 2018;10:641-52.

8 Chen Z, Hu H, Chen M, et al. Association of triglyceride to highdensity lipoprotein cholesterol ratio and incident of diabetes mellitus: 
a secondary retrospective analysis based on a Chinese cohort study. Lipids Health Dis 2020;19:33.

9 Cheng C, Liu Y, Sun X, et al. Dose-response association between the triglycerides: high-density lipoprotein cholesterol ratio and type 2 diabetes mellitus risk: the rural Chinese cohort study and metaanalysis. J Diabetes 2019;11:183-92.

10 Grundy SM, Stone NJ, Bailey AL, et al. 2018 AHA/ACC/AACVPR/ AAPA/ABC/ACPM/ADA/AGS/APhA/ASPC/NLA/PCNA guideline on the management of blood cholesterol: Executive summary: a report of the American College of Cardiology/American heart association Task force on clinical practice guidelines. Circulation 2019;139:e1046-81.

11 Zhao Y, Hu Y, Smith JP, et al. Cohort profile: the China health and retirement longitudinal study (CHARLS). Int $J$ Epidemiol 2014;43:61-8.

12 DeLong ER, DeLong DM, Clarke-Pearson DL. Comparing the areas under two or more correlated receiver operating characteristic curves: a nonparametric approach. Biometrics 1988;44:837-45.

13 von Eckardstein A, Schulte H, Assmann G. Risk for diabetes mellitus in middle-aged Caucasian male participants of the PROCAM study: implications for the definition of impaired fasting glucose by the American diabetes association. prospective cardiovascular Münster. $J$ Clin Endocrinol Metab 2000;85:3101-8.

14 Zhao J, Zhang Y, Wei F, et al. Triglyceride is an independent predictor of type 2 diabetes among middle-aged and older adults: a prospective study with 8-year follow-ups in two cohorts. J Trans/ Med 2019;17:403.

15 Liang Z, Qiu QY, Wu JH, et al. Alcohol drinking, dyslipidemia, and diabetes: a population-based prospective cohort study among inner Mongolians in China. Biomed Environ Sci 2016;29:555-62.

16 White J, Swerdlow DI, Preiss D, et al. Association of lipid fractions with risks for coronary artery disease and diabetes. JAMA Cardiol 2016;1:692-9.
17 Lotta LA, Sharp SJ, Burgess S, et al. Association between lowdensity lipoprotein cholesterol-lowering genetic variants and risk of type 2 diabetes: a meta-analysis. JAMA 2016;316:1383-91.

18 Mach F, Baigent C, Catapano AL, et al. 2019 ESC/EAS guidelines for the management of dyslipidaemias: lipid modification to reduce cardiovascular risk. Eur Heart J 2020;41:111-88.

19 Lin D, Qi Y, Huang C, et al. Associations of lipid parameters with insulin resistance and diabetes: a population-based study. Clin Nutr 2018;37:1423-9.

20 Song $\mathrm{Q}$, Liu X, Wang A, et al. Associations between non-traditional lipid measures and risk for type 2 diabetes mellitus in a Chinese community population: a cross-sectional study. Lipids Health Dis 2016;15:70.

21 Seo MH, Bae JC, Park SE, et al. Association of lipid and lipoprotein profiles with future development of type 2 diabetes in nondiabetic Korean subjects: a 4-year retrospective, longitudinal study. J Clin Endocrinol Metab 2011;96:E2050-4.

22 Zhu X-W, Deng F-Y, Lei S-F. Meta-Analysis of atherogenic index of plasma and other lipid parameters in relation to risk of type 2 diabetes mellitus. Prim Care Diabetes 2015;9:60-7.

23 Wada M, Yano S, Hamano T, et al. Effect of serum cholesterol on insulin secretory capacity: Shimane CoHRE study. PLoS One 2016;11:e0149452.

24 Fryirs MA, Barter PJ, Appavoo M, et al. Effects of high-density lipoproteins on pancreatic beta-cell insulin secretion. Arterioscler Thromb Vasc Biol 2010;30:1642-8.

25 Bardini G, Rotella CM, Giannini S. Dyslipidemia and diabetes: reciprocal impact of impaired lipid metabolism and beta-cell dysfunction on micro- and macrovascular complications. Rev Diabet Stud 2012;9:82-93.

26 Vaiserman A, Lushchak O. Developmental origins of type 2 diabetes: focus on epigenetics. Ageing Res Rev 2019;55:100957.

27 Gilbert ER, Liu D. Epigenetics: the missing link to understanding $\beta$-cell dysfunction in the pathogenesis of type 2 diabetes. Epigenetics 2012;7:841-52. 